\title{
Influence of local factors on the distribution of snow resources in northern Tien Shan
}

\author{
S. I. SeVErskiy AND I. V. SEVERSKiY \\ Laboratory for Monitoring Hydrological Systems, Institute of Space Research of the Academy of Sciences of Kazakh SSR, \\ Pushkin st. 125, Alma-Ata 480021, USSR
}

\begin{abstract}
Methods of quantitative evaluation of the influence of local factors such as slope exposure (aspect and gradient) and types of vegetation on the distribution of snow cover found in the northern Tien Shan are described. This investigation is based on regular measurements of snow depth and density at different altitudes and exposures, and with different vegetation types. A strong statistical relationship was obtained between snow cover on the one hand and slope exposure and vegetation types on the other. Local factors have a stronger influence on the distribution of snow cover than elevation. These methods were used for the estimation of the distribution of snow cover in a typical river basin. The results obtained differ significantly from the results of evaluations made by traditional methods.
\end{abstract}

\section{THE PROBLEMS AND INITIAL DATA}

Shortage of water in arid areas of Central Asia is one of the factors limiting economic development and ecological stability in the region. The main renewable water resource here is runoff from snow cover. Thus we need to evaluate the distribution and regime of the snow cover. Among the main aspects of this problem the influence of local factors such as slope exposure (aspect and gradient), type of vegetation, and wind-blown transfer of snow in mountains have been least investigated. Most stations in the northern Tien Shan mountains are located on the northern slopes or bottoms of valleys, and these observations do not take into account the influence of such local factors on the distribution of snow cover.

In the present paper, an attempt is made to evaluate quantitatively the influence of these local factors on the distribution of snow cover in the northern Tien Shan. This evaluation is based on regular measurements of snow depth and density in different years at between 40 and 60 observation posts in special study areas in the Turgen, Bolshaya Almatinka and Malaya Almatinka river basins in the Zailiyskiy Alatau. Measurements were obtained regularly between 1970 and 1989, and in more detail between 1983 and 1989. They were accompanied by continuous meteorological observations in the Turgen river basin at the winter avalanche station of the Geography Institute of the Kazakh Academy of Sciences. Standard hydrometeorological observations in the mountains of Central Asia and Kazakhstan, and the results of the previous investigations closely associated with the given problem, were also used in this study. Study areas were located at altitudes from 1600 to $3000 \mathrm{~m}$ on slopes of typical steepness $\left(20\right.$ to $\left.30^{\circ}\right)$ with different orientations (relative to the Sun) and vegetation types.

\section{INFLUENCE OF SLOPE EXPOSURE}

Past work on the influence of slope exposure on the distribution of peak snow storage (Iveronova, 1956; Severskiy and Blagoveshenskiy, 1983; Sosedov, 1967) was supported by the results of the study reported here. Previous studies permitted using measurements on north slopes for reliable determination of maximum water storage in snow cover only in the case of snow cover on south slopes. The problem of calculating snow storage for other azimuths remained unresolved.

We attempted to solve this problem by calculating the radiation balance for different slopes. We assumed that the difference in snow storage on slopes of different orientation, with otherwise equivalent conditions, was determined mainly by variations in insolation-induced snowmelt and evaporation.

We simplified the calculation of radiation input by estimating the energy received by a slope as proportional to the exposure coefficient, $A$, which characterizes the slope position towards the Sun, and specified the slope azimuth, $A_{\mathrm{z}}$, its steepness, $\gamma$, and the altitude of the Sun over the horizon, $\xi$,

$$
A=\sin \left(A_{\mathrm{z}} / 2\right) \sin (\xi+\gamma) .
$$

For slopes in the northern quadrant, $\gamma$ is considered negative. Values of $\xi$ for slopes of any orientation were taken as equal to the Sun's altitude at noon and were determined on the date of the snow survey at a given site. 


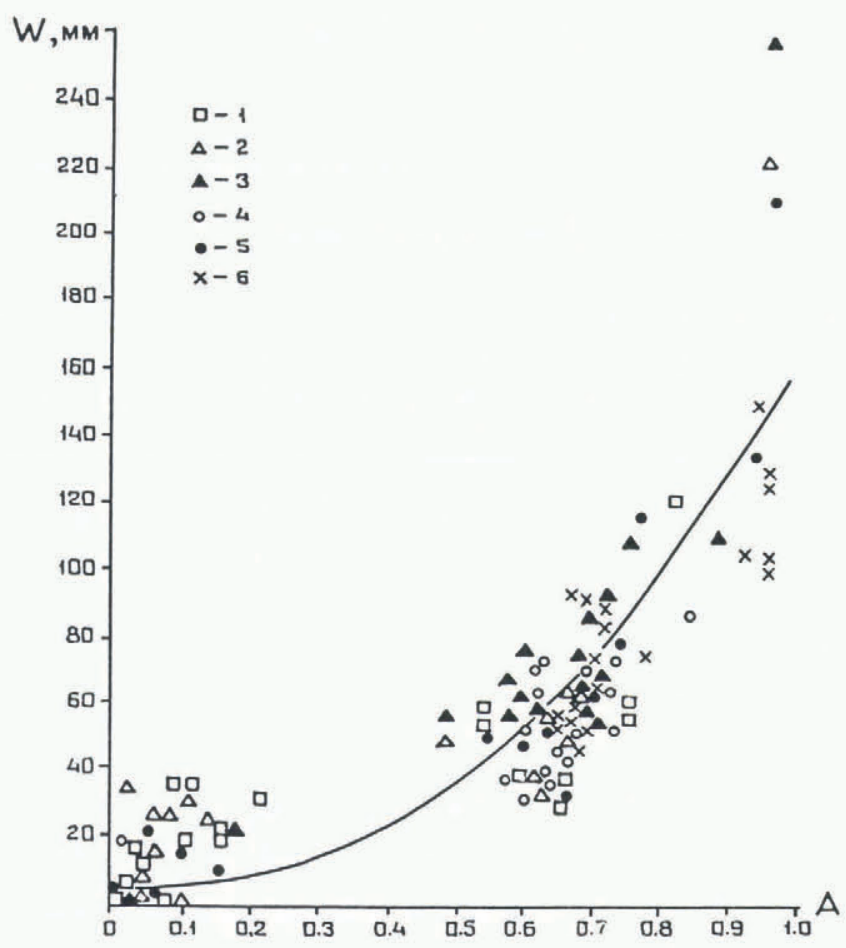

Fig. 1. Relationship between $A$ and $\triangle W$. Years and module ratio of snow storage $(C)$. (1) 1986, $C=0.90$; (2) $1987, C=1.32$; (3) $1985, C=1.38$; (4) 1984 , $C=0.66$; (5) $1988, C=1.54$; (6) in the years from 1971 to 1983. Here $C=W_{\mathrm{e}} / W_{\mathrm{m}}$ where $W_{e}$ is the maximum snow storage for the year and $W_{\mathrm{m}}$ is the mean defined by long-term maximum snow-storage data.

As a measure of the difference in snow storage on meadows (grass-covered) of various orientations, we used the value:

$$
\Delta W=W_{\mathrm{n}}-W_{\mathrm{a}},
$$

where $W_{\mathrm{n}}$ is the snow storage on slopes of northern orientation and $W_{\mathrm{a}}$ is the snow storage on slopes of any orientation at the same altitude, $H$.

Comparing the results of simultaneous snow surveys on meadow slopes of different exposures with equality of their absolute altitude, $H$, we get the relation

$$
\Delta W=F(A) .
$$

For maximum snow storage this dependence (Fig. 1) is a parabola of the second order

$$
W=10-51 A+194.8 A^{2}
$$

with a correlation coefficient of 0.89 . Using data from standard snow observations on north slopes and slope exposure, we calculated the snow storage $W_{\max }$ on different slopes. A comparison of these values with the corresponding data of snow observations revealed an average error of $\pm 10 \%$ (at $W<600 \mathrm{~mm}$ ). Calculated by this equation, exposure coefficients for snow on southern, eastern and western slopes coincided closely with ones obtained in the standard observations. We concluded that values of $W_{\max }$ calculated in this way for slopes of any arbitrary exposure are close to the actual ones.

Equation (2) permits prediction of maximum snow storage on slopes of any exposure by the average zonal (background) values of maximum snow storage defined by data from standard snow observations and corresponding indices of slopes having this exposure. Systematic spatial changes in heat and moisture exchange on slopes in mountain regions are reflected in the relation $\Delta W=F(A)$. The relatively small error permits us to recommend Equation (2) for practical use in determination of snow storage for snow avalanche calculations and water resource evaluation.

The exposure coefficient, $A$, characterizes simultaneously the altitude of the Sun, aspect and slope gradient, and should be used in mountain regions of Central Asia, and other areas where radiation is the dominant influence on snowmelt.

\section{INFLUENCE OF VEGETATION TYPES}

The influence of vegetation type upon snow-cover distribution was investigated with the data from synchronous snow surveys at 40 to 60 sites with different types of vegetation, but with $A_{\mathrm{z}}, \gamma$, and $H$ constant, obtained in 1983-88 at the Zailiyskiy Alatau. In the early part of the field surveys, we estimated the number of measurements of snow depth, $n_{\mathrm{h}}$, and density, $n_{\mathrm{p}}$, for slopes with different types of vegetation needed to determine the snow storage accurately. The investigations showed that the necessary number of measurements with these characteristics decreases rapidly with the increasing snow storage and with the transition from forest-covered to grass-covered (meadow) slopes (Table 1 ). All further measurements of depth, $h$, and snow density, $p$, at the control sites were made taking these results into consideration.

The influence of vegetation type upon the total snow resource was expressed through a dimensionless coefficient, $K_{\mathrm{p}}$, the ratio of water storage in snow cover at the site with given vegetation type to snow storage on the meadow slope with the same $A_{\mathrm{z}}, \gamma, H$.

Using simultaneous measurements, relations of the form $K_{\mathrm{p}}=F(W)$ were obtained for coniferous forests and shrubs including differently closed crowns (Fig. 2). Analogous relations were obtained for the hardwood forest. For all gradations of closed crowns of wood and shrubs, for slopes with different vegetation types, equations were derived which permit estimation of $K_{\mathrm{p}}$ (with average error $\pm 10 \%$ ) using mean zonal (background) values, $W$, for slopes with different vegetation types. In Table 2 these equations for wood and shrub vegetation with fixed closed crowns are given as examples.

The results obtained show that in regions of shallow and moderate snow, slope orientation and vegetation type influence the snow-cover distribution significantly more than does the absolute altitude. At vertical gradients of snow cover typical for the Zailiyskiy Alatau, the change of orientation from north to east or west by degree of influence on maximum snow storage as a decrease in altitude of almost $1000 \mathrm{~m}$ (within the middle mountain belt). Transition from the meadow surfaces to slopes covered with hardwood forest is equal to the change from a northern orientation to an eastern or western orientation. The decrease in snow storage related to the 
Severskiy and Severskiy: Snow cover in northern Tien Shan

Table 1. Necessary number of measurements of snow depth, $n_{\mathrm{h}}$, and density $n_{\mathrm{p}}$, in relation to snow water equivalence and vegetation types

Vegetation type Character

Corresponding number of measurements of snow depth and density

Water storage in snow cover

$50 \mathrm{~mm} \quad 100 \mathrm{~mm} \quad 150 \mathrm{~mm} \quad 200 \mathrm{~mm} \quad 250 \mathrm{~mm} \quad 300 \mathrm{~mm} \quad 350 \mathrm{~mm} \quad 400 \mathrm{~mm}$

$\begin{array}{lrrrrrrrrr}\begin{array}{l}\text { Meadow, meadow } \\ \text { with open shrubs, } \\ \text { hardwood forest }\end{array} & n_{\mathrm{h}} & 36 & 21 & 12 & 7 & 5 & 3 & 2 & (2) \\ & n_{\mathrm{p}} & 9 & 6 & 4 & 3 & 3 & 3 & 2 & 2 \\ \text { Shrubs } & n_{\mathrm{h}} & 56 & 34 & 23 & 16 & 11 & 7 & (5) & (4) \\ & n_{\mathrm{p}} & 14 & 8 & 5 & 4 & 3 & 3 & (3) & (2) \\ \text { Coniferous forest } & n_{\mathrm{h}} & 86 & 118 & 70 & 48 & (37) & (30) & (24) & \\ & n_{\mathrm{p}} & - & 17 & 9 & 7 & 5 & 5 & (4) & (4)\end{array}$

Note. Meadow-shrub associations with shrub crown density less than 0.3 are referred to "meadow with open shrubs".

transition from meadow surfaces to coniferous forest (at typical planting density of $0.4-0.6$ ) is more than twice the decrease in snow storage corresponding to a decrease in absolute altitude from 2500 to $1500 \mathrm{~m}$.

Relationships dependent on vegetation types are only applicable to the region in which they were developed. They can be used for corresponding areas in the

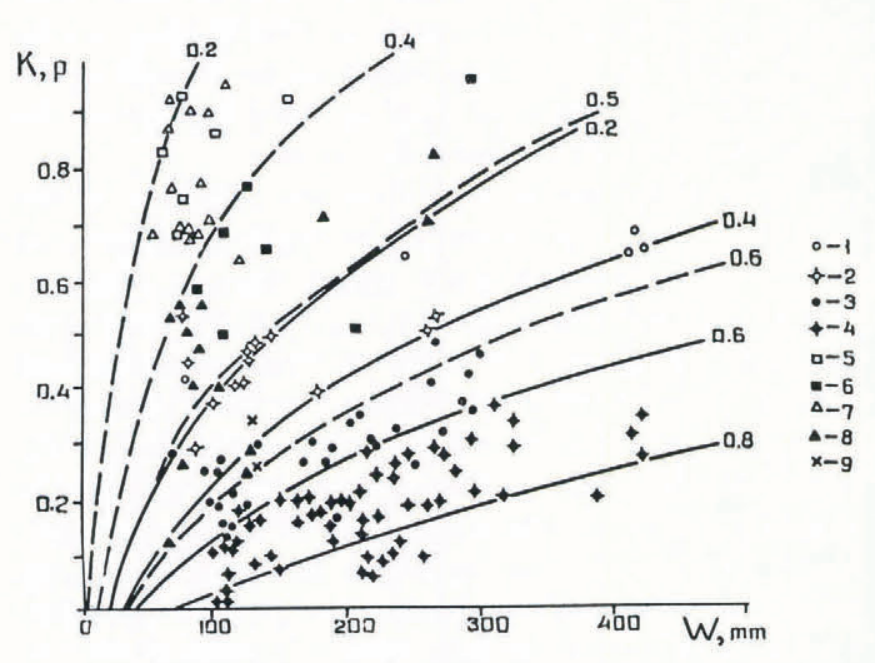

Fig. 2. Relationship between snow water equivalence on meadow slopes and $K_{\mathrm{p}}$ for different vegetation types. Figures on curves indicate crown density. (1) glade in coniferous forest less than $20 \mathrm{~m}$ wide; (2) coniferous forest with crown density $0.3-0.4$; (3) coniferous forest with crown density 0.5-0.6; (4) coniferous forest with crown density 0.7-0.8; (5) coniferous bushes with crown density $0.3-0.4 ;(6)$ coniferous bushes with crown density 0.50.6 ; (7) deciduous bushes with crown density 0.3-0.4; (8) deciduous bushes with crown density 0.5-0.6; (9) all types of bushes with crown density less 0.3.
Zailiyskiy Alatau and in regions of northern Tien Shan with similar winter characteristics. In other regions these relationships may be different. In regions with a more intense wind regime, the correlation of the snow storage on meadow and forest slopes may be reversed, as more wind-transported snow accumulates in the forest. However, the methods presented here might be useful in other mountain regions.

\section{APPLICATION TO DISTRIBUTION OF SNOW RESOURCES IN MALAYA ALMATINKA RIVER BASIN}

The relationships derived herein (Figs 1 and 2) were used to determine the snow resources and their distribution in the Malaya Almatinka river basin. In this region the mean zonal (background) values of maximum snow

Table 2. Example of equations for different vegetation types at crown density 0.4 (in fractions unit)

Vegetation type

Design equation

Mean-square error

Coniferous forest $\quad K_{\mathrm{p}}=0.018(W-25)^{0.60} \quad \pm 0.025$ (Tien Shan spruce)

Hardwood forest $\quad K_{\mathrm{p}}=0.050(W-20)^{0.48} \quad \pm 0.043$ (aspen, birch, fruit)

Shrubs

$$
K_{\mathrm{p}}=0.064(W-15)^{0.53}
$$




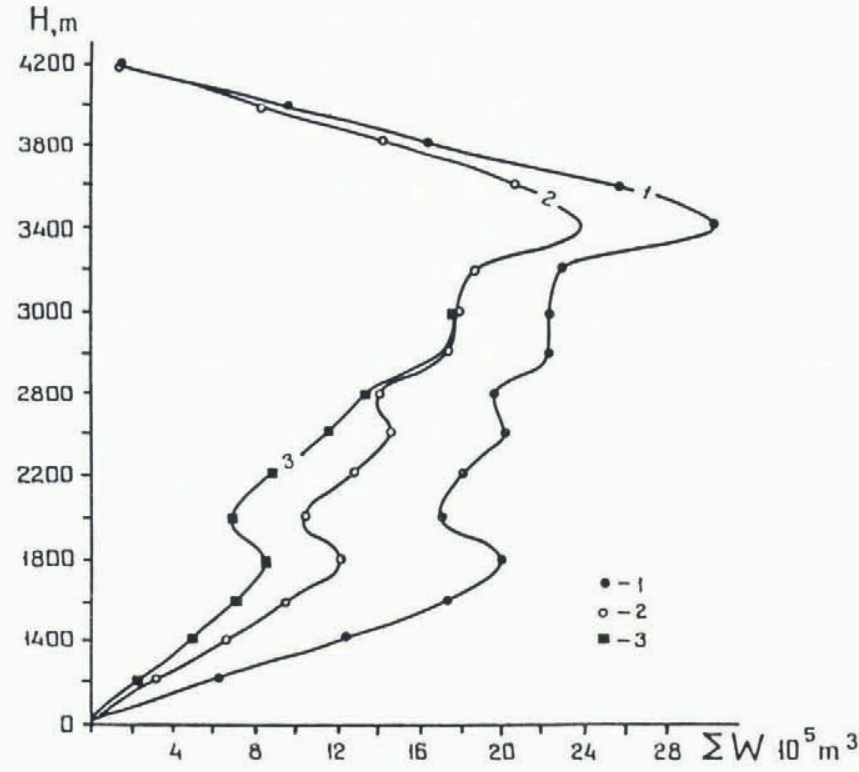

Fig. 3. Distribution of snow-storage volume (water equivalent) $\Sigma W$ with absolute altitude $H$ in the Malaya Almatinka river basin, (1) using mean zonal (background) values of maximum snow storage, not considering the local factors; (2) taking influence of slope exposure into consideration; (3) taking influence of slope exposure and vegetation into consideration.

storage were determined by the relation $W_{\max }=F(H)$ based on long-term snow-cover data of standard observations. Equation (2) and Table 2 were used to convert the mean zonal values $W_{\max }$ to corresponding values of the real surfaces of the mountain slopes. The design was made by node points of the uniform grid by maps scaled at 1:10000, through every $250 \mathrm{~m}$. All measurements (including determination of parameters $H, A_{\mathrm{z}}, \gamma, B$ at $\xi=$ constant) were made for 2000 points (here $B$ is vegetation type). Figures 3 and 4 show that estimates of peak snow storage based on exposure and vegetation are less than $30 \%$ of estimates determined by the relation $W_{\max }=F(H)$ alone. Thus conventional means of estimating snow storage appear to overestimate mountain snow storage in comparison with the real value by about one-third. Such errors raise doubts about waterbalance evaluations and runoff forecasts.

Our results (Fig. 3) show that slope exposure is an important influence throughout the full range of altitudes, and the intensity of this influence decreases with altitude as snow storage increases. The influence of vegetation gradually increases through the transition from hardwood forest to mixed forest and thence to coniferous forest. The primary influence of these local factors on snow-cover distribution is at middle elevations in the mountain belt. Snow storage calculated here by considering the influence of slope exposure and vegetation type is less than $55 \%$ of that calculated from altitude alone. These results may improve the determination of snow distribution and total storage of snow water equivalence in mountains. Based on these results, $50 \%$ of the snow resources of the Malaya Almatinka river basin are found above $3100 \mathrm{~m}$ in only $25 \%$ of the total basin area. Because the soil at these high elevations remains frozen until the snow cover melts

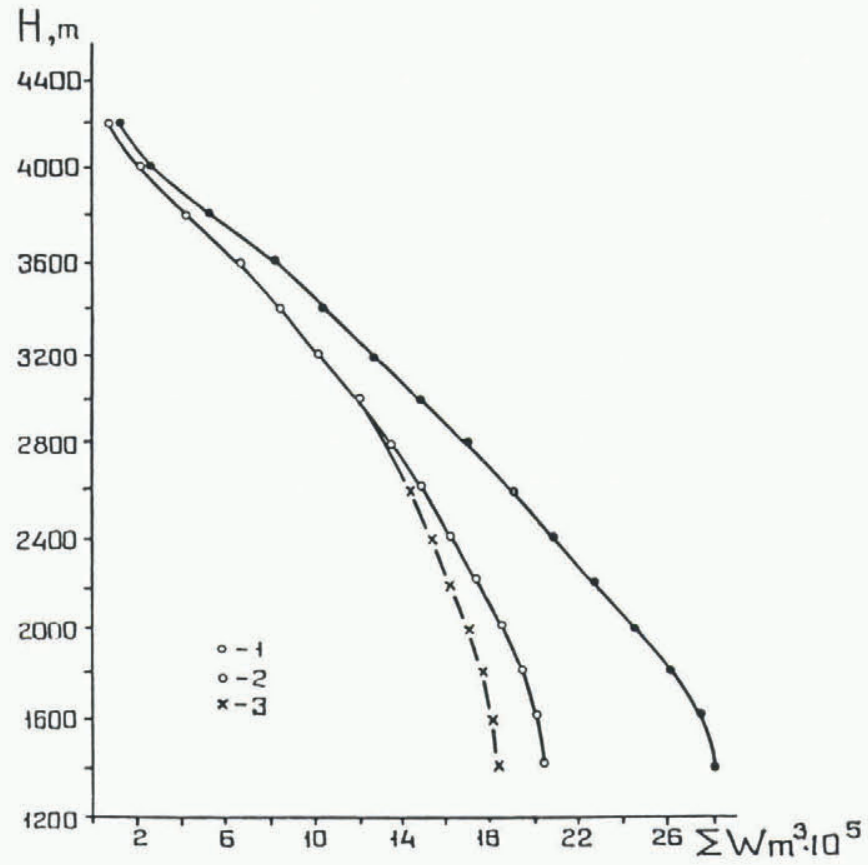

Fig. 4. Cumulative snow storage from high to low altitude in the Malaya Almatinka river basin, calculated: (1) using mean zonal (background) values of maximum snow storage, not considering the local factors; (2) taking influence of slope exposure into consideration; (3) taking influence of slope exposure and influence of vegetation type into consideration.

(Severskiy, 1978; Severskiy and Blagoveshenskiy, 1983), production of snowmelt runoff from the high mountains is highly efficient and is a critical water resource.

\section{CONCLUSIONS}

The influence of wind on snow distribution is considered to be minor in the forest zone of the northern Tien Shan and other mountain ranges of Central Asia and Kazakhstan (Severskiy, 1978; Severskiy and Blagoveshenskiy, 1983). Wind redistribution of snow was not considered in this study and will require detailed studies to determine its importance.

Influences of slope exposure and vegetation type on distribution of snow cover in northern Tien Shan have been shown to be large enough to merit consideration when assessing water resources and evaluating avalanche hazards.

In northern Tien Shan, as well as in other mountain regions of Kazakhstan and Central Asia, the slope exposure and vegetation type have a significantly greater influence on the snow-cover distribution than does the absolute altitude.

The total influence of these local factors is most important at middle elevations. Their influence decreases with increasing snow cover and with the transition to higher elevations.

Most of the snow cover that supplies water to mountain rivers in Kazakhstan and Central Asia is found within the small proportion of the area, at altitudes above $3000 \mathrm{~m}$. Further studies are needed 
regarding the characteristics of snow cover in this high mountain zone.

\section{REFERENCES}

Iveronova, M.I. 1956. Nekotoryye zakonomernosti raspredeleniya i rezhima snezhnogo pokrova na gornykh sklonakh $\mathrm{v}$ leso-lugovo-stepnom poyase Terskey-Ala-Tau [Naturally determined distribution of snow cover on slopes in forest-meadow belt on Terskey Alatau]. Trudy Instituta Geografii, 67(5), 11-36.
Severskiy, I. V. 1978. Snezhnyye laviny Zailiyskogo i Dzhungarskogo Alatau [Snow avalanches of the Zailiyskiy and Dzhungarskiy Alataus]. Alma-Ata, "Nauka", Kazakhskoy SSR.

Severskiy, I. V. and V. P. Blagoveshenskiy. 1983. Estimation of avalanche hazard of mountain area. Alma-Ata, "Nauka", Kazakhskoy SSR.

Sosedov, I.S. 1967. Research of snow water's balance at mountain slopes. Alma-Ata, "Nauka", Kazakhskoy SSR.

The accuracy of references in the text and in this list is the responsibility of the author/s, to whom queries should be addressed. 